\title{
Editorial
}

\section{Resilience, Solidarity and Agency}

\section{Siphamandla Zondi}

University of Johannesburg

Editor in Chief

\section{DOI - https://doi.org/10.35293/srsa.v43i1.3550}

The Covid period has made issues of solidarity and isolation particularly important in society today. Adversity tends to cause society to drift towards despair, the survival of the fittest and development that leave many behind. We have seen enough of this with many crises that African societies have confronted including violence, crime, governance crises, terrorism and health calamities. Yet, these crises have already generated interest in ways of building resilience through solidarity and cooperation.

The papers in this collection in different ways stimulate ways of thinking about human solidarity and cooperation both in responses to threats to living well as well as to opportunity for fashioning better futures. Bidandi describes how these solidarity networks come from familial systems around which society is organised, pointing out some of the threats to this age-old social fabric. Molapo analyses how African religious thinking in families and communities has affected how people understand and respond to the Covid-19 crisis today, suggesting this is turn to relationality in face of the alienation crises induce. Just how the police culture may be changing in ways that enable comprehensive crime responses are the subject of Maweni's paper. The paper by Sadiki and Steyn analyses the plight of the homeless people in Tshwane in the face of growing criminality and how the victims might understand their conditions in society. Sooliman reflects critically on the idea of the transformation of the university, focusing on how they could be transformed into spaces of co-existence and continuity of life rather than violence and death.

Rapanyane's paper focuses on the problem of terrorism in Nigeria and how funds are mobilised in support of terror. It discusses this to offer suggestions on how to minimise terror mobilisation. Makone suggests the concept of a hybrid 
regime as useful to guide our understanding of the long-standing governance crisis in Zimbabwe. Phaahla describes the significance of the Communist Party of China as a crucial political institution behind the rise of China and distils lessons for political parties. Ndzendze uses trade data to argue that the relationship between South Africa under Thabo Mbeki and Vladimir Putin's Russia was much more significant in relation to economic cooperation than it is realised. Pillay grapples with whether China has exported to South Africa the propaganda model of manufacturing consent in society and whether this explains limited criticism of China's conduct in the South African media.

All these discussions point to the significance of developments that become apparent at the confluence of resilience, solidarity and agency. They demonstrate individually which of these three are significant. They may lead to a greater understanding of how resilience is affected by violence, terror, governance crisis, crime patterns, the institutional cultures in law-enforcement agencies, economic cooperation, and failures in education. These also affect agency and solidarity patterns in Africa. 